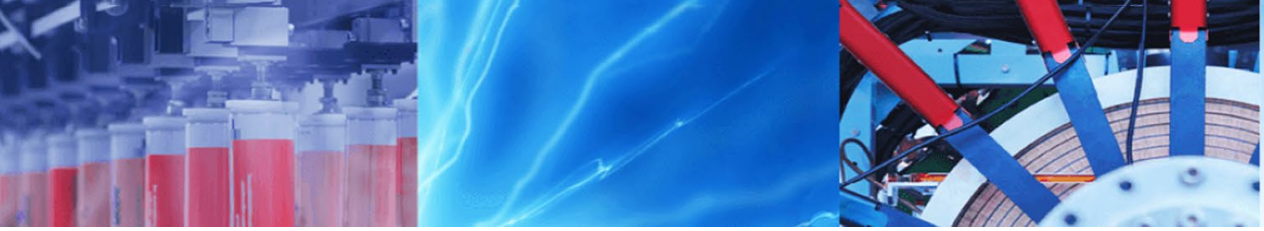

Research Article

\title{
Multi-response parametric optimisation of abrasive waterjet milling of Hastelloy C-276
}

\author{
G. Gopichand ${ }^{1}$ (D) M. Sreenivasarao ${ }^{2}$
}

Received: 11 March 2020 / Accepted: 15 September 2020 / Published online: 4 October 2020

(c) Springer Nature Switzerland AG 2020, corrected publication 2020

\begin{abstract}
Abrasive waterjet (AWJ) milling is a rapidly evolving research topic in the development of unconventional methods for machining high-strength materials without affecting their physical and thermal properties. It is considered as a promising technique for machining milling pockets in Hastelloy C-276. In the present study, the AWJ milling behaviour of Hastelloy C-276 was examined with the purpose of evaluating the performance parameters, namely the material removal rate and surface roughness $\left(R_{\mathrm{a}}\right)$. The considered input process parameters included the waterjet pressure, step over, traverse rate, and abrasive flow rate. The response surface methodology with a Box-Behnken design was used to perform the experiments, which involved 29 machining runs. Analysis of variance was used to identify the significant parameters of the machining process, and the optimal process parameter combination for achieving a high material removal rate and low surface roughness was established with the aid of response surface graphs. Multi-response optimisation based on grey relational analysis was also performed taking into consideration the overall output response. The waterjet pressure and traverse rate were identified as the primary determinants of the material removal rate, whereas the step over was the predominant factor of the surface roughness. The selected AWJ milling conditions based on grey relational analysis approach were examined using surface morphology, surface topography of milled pockets on Hastelloy C-276.
\end{abstract}

Keywords Abrasive waterjet · Hastelloy C-276 · Pocket milling · Grey relational analysis · Surface morphology · Surface topography

\section{Introduction}

A major issue in the manufacturing industry is the machining of high-strength materials including metals, non-metals, ceramics, composites, and nickel-based alloys. Abrasive waterjet (AWJ) machining is one among the promising methods for addressing the challenge owing to its applicability to a wide range of processes such as cutting, drilling, turning, and milling [1-4]. Among the various AWJ machining applications, pocket milling is one of the most important, involving the utilisation of the original concept of AWJ milling as a non-through cut industrial process. The extensive use of AWJ milling in industry has confirmed its superiority to the conventional pocket milling process. The utilisation of AWJ milling method in the automotive and aerospace sectors, among others, has enabled the avoidance of some of the problems associated with conventional pocket milling [4-6], which include tool breakage, excessive tool wear, workpiece burnishing (due to tool dullness, too shallow cut depth, or too small radial relief angle), and the production of chatter marks (due to insufficient stiffness of the system and external vibration). In addition, and more specifically, the machining cost of Hastelloy C-276 (ASTM B575) using conventional methods has been high owing to the rapid tool wear caused by the hardness of the material and the low material removal rate. Hastelloy C-276

G. Gopichand, gogineni67@gmail.com | 'Department of Mechanical Engineering, AAR Mahaveer Engineering College, Hyderabad, Telangana 500 005, India. ${ }^{2}$ Department of Mechanical Engineering, JNTUH College of Engineering, Hyderabad, Telangana 500085, India. 
has numerous applications such as in power generators, waste treatment equipment, reactors, heat exchangers, evaporators, marine vehicles, and equipment used in the petrochemical, paper, and chemical industries. Some major problems are encountered during the machining of Hastelloy $\mathrm{C}-276$, including the occurrence of very high thermal and mechanical tool loads. This results in excessive tool wear and necessitates the use of low cutting speeds, which increases the machining time, and hence the cost. Milling using abrasive waterjet has been introduced by Hashish in 1987 [4]. Subsequently, many researchers started using the abrasive water jet for milling. Ojmerta et al. [7] introduced a milling concept referred to as discrete milling, which is similar to multiple-pass cutting, in which the cut depth is controlled within a closed boundary on a flat surface of the workpiece. The process is generally known as pocket milling. Hashish [8] developed a pocket milling technique for creating isogrid patterns in aluminium and titanium to increase the strength of the materials. Some researchers have carried experiments on the removal rate of material by Abrasive Waterjet Milling and presented their observations. Paul et al. $[9,10]$ found that the milling time increased with the milling depth, although not linearly, and with the degree of nonlinearity increasing with the machinability index. The material removal rate (MRR) was also observed to increase with decrease in grit size owing to the increased energy impact, resulting in a smoother surface finish. Shipway et al. [11] observed that the MRR decreased with increase in traverse rate and decrease in grit size, but that the traverse rate did not independently affect the MRR. Other researchers investigated the impact of standoff distance on milling MRR and surface finish in abrasive waterjet milling. Gupta et al. [12] found that the cut width significantly depended on the standoff distance because of the radial expansion of the jet. Haghbin et al. [13] reported that the core region of the submerged and unsubmerged waterjet did not break up into water droplets for standoff distances of $2-5 \mathrm{~mm}$, and that the particle velocity was not significantly influenced by an increase in the standoff distance up to $5 \mathrm{~mm}$. Momber and Kovacevic et al. [14] and Hashish et al. [4] also obtained similar results with increase in standoff distance, which results in exposure of a larger portion of the jet and a decrease in MRR. Some researchers have reported the effect of pressure on abrasive waterjet milling through their investigations. Kong [15] found that the MRR increased with increase in pressure, accompanied by uniform material erosion and low surface waviness. Haghbin et al. [16] comparatively investigated AWJ milling and high-pressure abrasive slurry jet milling and observed that the surface waviness and metal erosion of the former were higher. They also observed that the jet-impinging diameter was larger when the jet was unsubmerged compared with when it was submerged, resulting in an increase in the channel width for a given depth. The core diameter of the jet was the same for both cases. Some researchers have stated through their investigations that traverse rate is very important in abrasive water jet milling and that its effect on material removal can have a significant impact on grit embedding on the surface finish. Paul et al. [17] found that the traverse speed was sufficiently high during pocket milling with nearly no material removal occurring through micro-cutting or erosion. They also observed that the standard of distance (SOD) negligibly impacted the cut depth. Flower et al. [18] found that the grit embedment decreased with increase in traverse speed of the jet and decrease in impingement angle. However, the milling direction significantly affected the grit embedment, but the particle size had no effect. Flower et al. [19] noted a significant decrease in the MRR with increase in traverse speed, with greater surface waviness also occurring at lower traverse speeds. Flower et al. [19] also observed an increase in the MRR with increase in pressure irrespective of the traverse speed. Some researchers have used certain types of abrasives for their investigations and have also reported their effects on abrasive waterjet matching. Kanthababu et al. [20] posited that garnet afforded better performance compared with other abrasive materials such as $\mathrm{Al}_{2} \mathrm{O}_{3}, \mathrm{SiC}$, steel, and glass. Kanthababu et al. [21] reported the effects of the process parameters when using recycled garnet abrasives for machining. They noted that a \#85 garnet mesh provided a better surface finish and cut depth. Flower et al. [22] also observed that a garnet abrasive provided the highest MRR owing to its high particle hardness. Flower et al. [22] further investigated the effect of the particle hardness and shape on the MRR and $R_{\mathrm{a}}$ and found that both the MRR and $R_{\mathrm{a}}$ increased with increase in particle hardness. Few researchers have done their investigations on the nozzle and orifice and also published their significance. Chen et al. [23] observed that the jet diverged during ejection from the nozzle, with the deviation increasing the transverse speed and forming a striation. Paul et al. [17] found that a ratio of the nozzle diameter to the orifice diameter of 3.5-5.0 maximised the MRR. They also observed that the ratio of the hardness of the substrate to that of the particle was more important than the particle shape. In addition, some researchers have applied an abrasive waterjet to the milling of nickel-based alloys [24, 25].

The purpose of the present study was to investigate the effects of the process parameters of AWJ milling on the MRR and surface roughness and to use a 
multi-response optimisation technique to optimise the parameters. In addition, 29 pocket milling experiments were performed on Hastelloy C-276 workpieces to determine the best milling conditions for the material through comparison of the surface morphologies and topographies of the milled specimens.

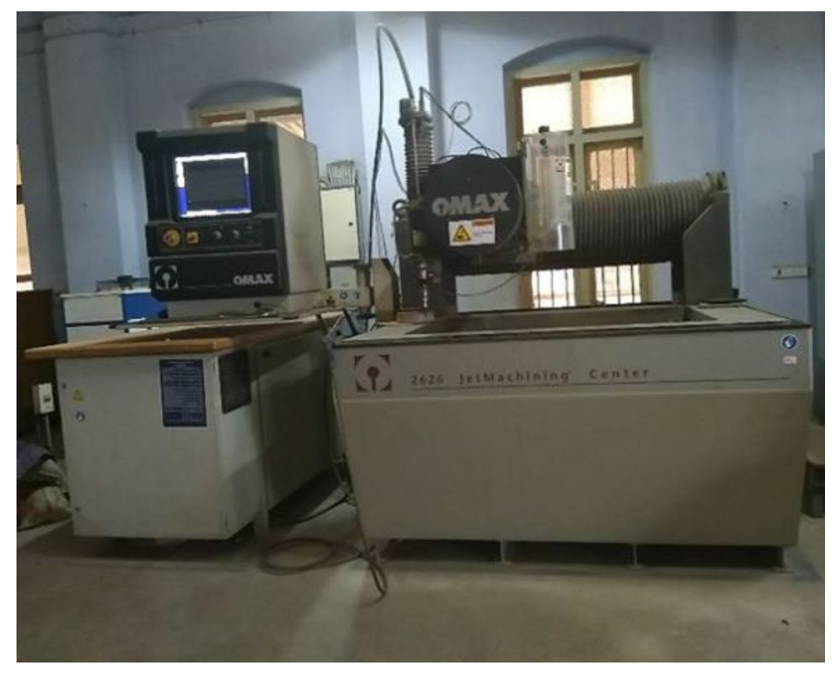

Fig. 1 Waterjet machining centre (model OMAX2626)

\section{Materials and methods}

The AWJ milling experiments were conducted using a precision waterjet machining centre (model 2626) manufactured by M/s OMAX Corporation at Fig. 1. Numerous machining parameters were involved but only the most important parameters were analysed, namely the waterjet pressure (P), step over (SO), traverse rate (TR), and abrasive flow rate (AFR). Various parameters involved in AWJM are shown in Fig. 2. These four parameters were, respectively, adjusted to three levels during each of the experiments Table 1. A garnet abrasive with \#85 mesh and a SOD of $2 \mathrm{~mm}$ were employed in the experiments. Table 2 gives the physical properties of the Garnet [14] and Fig. 3 shows the size distribution of the garnet used in this work. The response surface methodology using the Box-Behnken design was used to investigate the effects of the four afore mentioned AWJ milling process parameters on the multiple responses of the milling performance. The experiments were conducted on Hastelloy C-276 workpiece specimens measuring $260 \times 110 \times 6 \mathrm{~mm}$. The composition of Hastelloy C-276 is given in Table 3. The hardness of the material was measured by conducting a Vickers hardness test at three different locations on a specimen. The average of the measured hardness values of $183.67 \mathrm{HV}$ was adopted.

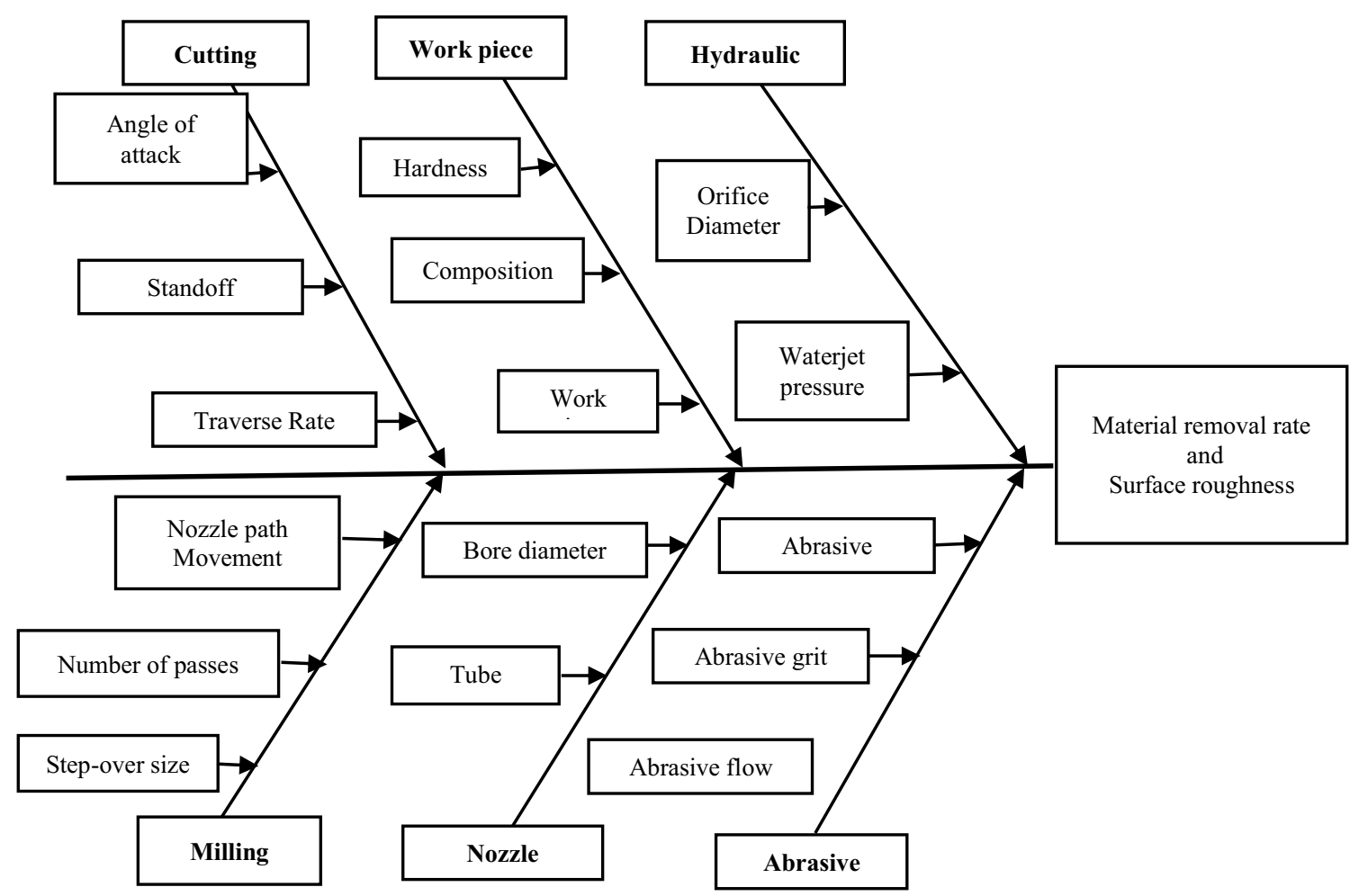

Fig. 2 Process parameters involved in AWJ Milling 
Table 1 AWJ milling process parameters and the considered values

\begin{tabular}{ll}
\hline AWJ milling parameters & Levels \\
\hline Waterjet pressure (P) MPa & $150,170,190$ \\
Step over (SO) $\mathrm{mm}$ & $0.2,03,0.4$ \\
Traverse rate (TR) $\mathrm{mm} / \mathrm{min}$ & $1500,2000,2500$ \\
Abrasive flow rate (AFR) kg/min & $0.22,0.32,0.42$ \\
Abrasive mesh size \# & 85 \\
Standoff distance $\mathrm{mm}$ & 2 \\
Jet impingement angle & $90^{\circ}$ \\
Orifice diameter $\mathrm{mm}$ & 0.35 \\
Nozzle diameter $\mathrm{mm}$ & 0.76 \\
\hline
\end{tabular}

Table 2 Physical properties of the garnet

\begin{tabular}{|c|c|}
\hline $\begin{array}{l}\text { Chemical classifica- } \\
\text { tion and composition }\end{array}$ & Silicate, $\mathrm{Fe}_{3} \mathrm{Al}_{2}\left(\mathrm{SiO}_{4}\right)_{3}$ \\
\hline Hardness & 7.5on Mohs scale \\
\hline Strength & Friable to tough \\
\hline Particle shape & Sharp, angular, irregular \\
\hline Cleavage & Irregular cleavage planes \\
\hline Transparency & Translucent \\
\hline Lustre & Vitreous \\
\hline Specific gravity & $3.9 \mathrm{~g} / \mathrm{cm}^{3}$ to $4.1 \mathrm{~g} / \mathrm{cm}^{3}$ \\
\hline Facet angles & $37^{\circ}$ to $42^{\circ}$ \\
\hline Colour & Red to pink \\
\hline Crystal system & $\begin{array}{l}\text { Cubic(isometric) system as rhombic } \\
\text { dodecahedrons or trapezohedrons or } \\
\text { combinations of the two }\end{array}$ \\
\hline
\end{tabular}

The hatch zigzag path strategy [24] was used to mill $20 \times 10 \mathrm{~mm}$ pockets in the Hastelloy C-276 workpiece specimens. The strategy involved the back-and-forth movement of an abrasive waterjet across the workpiece in the $X-Y$ plane with a predefined step over after $90^{\circ}$ turns. The process was repeated until the entire area was machined. A TESA IP67 coolant-proof digital Vernier calliper with a precision of $0.01 \mathrm{~mm}$ was used to measure the average cut depth, while a portable stylus-type profilometer was used to take three measurements of the surface roughness $\left(R_{\mathrm{a}}\right)$ of the machined specimen using a cut-off length of $0.8 \mathrm{~mm}$ and an evaluation length of $4 \mathrm{~mm}$. The average of the three measurements was adopted. The surface topography of a milled pocket was measured using a Taylor Hobson CCI non-contact roughness tester with a magnification of $20 \times$ and an $800-\mu m$ Gaussian filter. The details of the response surface methodology using the Box-Behnken design, are presented in Table 4. The MRR was calculated using Eq. (1). The milled pockets are shown in Fig. 4.
MRR $=$ Cut depth $\times$ Area of pocket/Milling time

\subsection{Multi-response optimisation and grey relational analysis}

Grey relations analysis (GRA), which is a multi-response decision-making method $[2,26]$, was used to investigate the complex relationship between the process parameters of the AWJ milling of Hastelloy C-276, namely MRR and $R_{\mathrm{a}^{\prime}}$ and how they impact the performance of the process. The GRA process involved three stages, as illustrated in Fig. 5 and described below.

Stage 1 Normalisation of the experimental results and calculation of the grey relational generation.

The raw data were pre-processed by normalisation based on the experimental results to avoid the effects of the different units and reduce the variability. The normalised values of the performance measures were expected to lie between 0 and 1 . For the normalised MRR, a larger value indicated better performance, as expressed by Eq. (2):

$X_{i j}=\frac{y_{i j}-\min \left(y_{i j}\right)}{\max \left(y_{i j}\right)-\min \left(y_{i j}\right)}$

In the case of the normalised $R_{\mathrm{a}}$ a smaller value indicated better performance, as expressed by Eq. (3)

$X_{i j}=\frac{\max \left(y_{i j}\right)-y_{i j}}{\max \left(y_{i j}\right)-\min \left(y_{i j}\right)}$

Here, for both MRR and $R_{\mathrm{a}}, X_{i j}$ is the value after the grey relational generation; $\max \left(y_{i j}\right)$ is the largest value of $y_{i j}$ for the $y$ th response; and $\min \left(y_{i j}\right)$ is the smallest value of $y_{i j}$ for the $y$ th response. Multi-response optimisation was used during the pre-processing of the GRA data for MRR and $R_{\mathrm{a}^{\prime}}$ and the optimal levels of the grey relational grade were used to obtain a higher MRR and lower $R_{\mathrm{a}}$.

Stage 2 Calculation of the grey relational coefficients (GRCs)

The grey relational coefficients (GRCs) were calculated to express the relationship between the ideal and actual normalised experimental values of MRR and $R_{a}$, as presented in Table 7. This was accomplished using Eq. (4):

$\xi_{i}(k)=\frac{\Delta_{\min }+\omega \Delta_{\max }}{\Delta_{o i}(k)+\omega \Delta_{\max }}$

where $\Delta_{o i}(k)$ is the absolute difference between $y_{o}(k)$ and $y_{i}(k) ; y_{o}(k)$ is the reference sequence $\left(y_{o}(k)=1\right.$, where $k=1$, $2, \ldots m$, where $m$ is the number of responses); and $y_{i}(k)$ is 

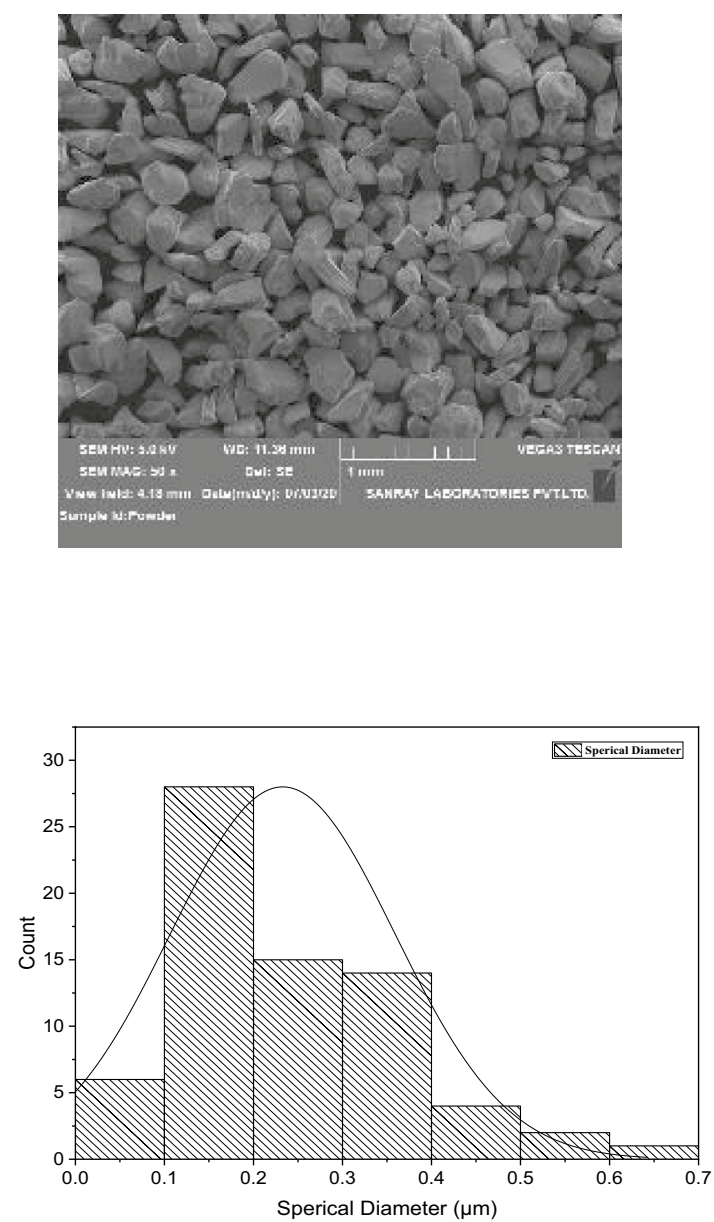

Fig. 3 Abrasive grain distribution curve

Table 3 Material composition of Hastelloy C-276

\begin{tabular}{ll}
\hline Element & Percentage (\%) \\
\hline Nickel & 58.73 \\
Chromium & 16.48 \\
Molybdenum & 15.05 \\
Iron & 5.13 \\
Tungsten & 3.75 \\
Manganese & 0.47 \\
Vanadium & 0.22 \\
Cobalt & 0.08 \\
Silicon & 0.08 \\
Carbon & 0.01 \\
\hline
\end{tabular}

the comparability sequence $(i=1,2, \ldots n$, where $n$ is the number of experimental values) Eqs. (5-7):

$\Delta_{o i}(k)=\left\|y_{o}(k)-y_{i}(k)\right\|$
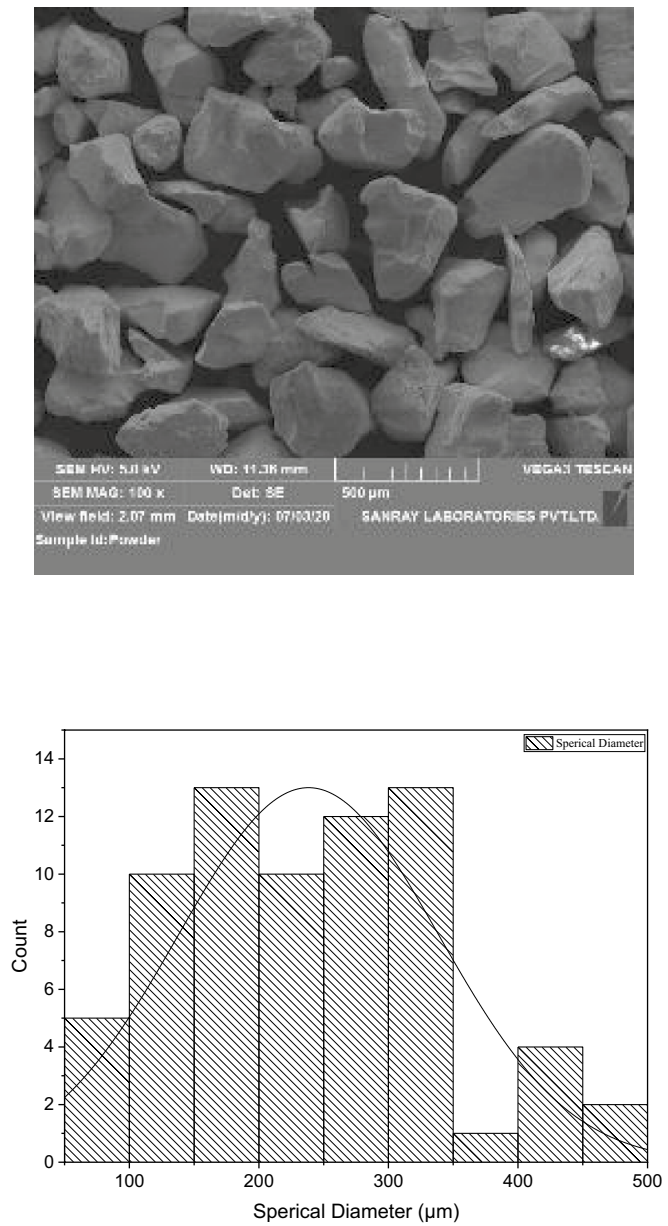

$\Delta \min =\operatorname{minmin}\left\|y_{o}(k)-y_{i}(k)\right\|_{\min }$

$\Delta \max =\operatorname{maxmax}\left\|y_{o}(k)-y_{i}(k)\right\|_{\max }$

where $y_{0}(k)$ is the sequence; $y_{i}(k)$ is the comparability sequence; and $\omega$ is the distinguishing or identification coefficient.

Stage 3 In this stage, the grey relational grade (GRG) is generated by obtaining the average GRC of the performance measures. All the obtained multi-performance measures are presented in Table 7. Based on the GRG, a rank is used to determine the optimal combination of the process parameters. The GRG is computed using Eq. (8):

$\gamma_{i}=\frac{1}{n} \sum_{k=1}^{n} \xi_{i}(k)$

where the GRG for the $j$ th experiment $k$ is the number of the performance characteristics. The normalised 
Table 4 Measurement details of MRR and $R_{\mathrm{a}}$

\begin{tabular}{|c|c|c|c|c|c|c|}
\hline \multicolumn{5}{|c|}{ AWJ milling process parameters } & \multicolumn{2}{|l|}{ Output responses } \\
\hline Exp no & $P(\mathrm{MPa})$ & $\mathrm{SO}(\mathrm{mm})$ & $\mathrm{TR}(\mathrm{mm} / \mathrm{min})$ & AFR (kg/min) & $\operatorname{MRR}\left(\mathrm{mm}^{3} / \mathrm{min}\right)$ & $\begin{array}{l}R_{\mathrm{a}} \\
(\mu \mathrm{m})\end{array}$ \\
\hline 1 & 150 & 0.2 & 2000 & 0.32 & 217.70 & 2.96 \\
\hline 2 & 190 & 0.2 & 2000 & 0.32 & 362.12 & 3.60 \\
\hline 3 & 150 & 0.4 & 2000 & 0.32 & 157.96 & 6.06 \\
\hline 4 & 190 & 0.4 & 2000 & 0.32 & 292.54 & 6.87 \\
\hline 5 & 170 & 0.3 & 1500 & 0.22 & 282.25 & 5.22 \\
\hline 6 & 170 & 0.3 & 2500 & 0.22 & 190.68 & 5.84 \\
\hline 7 & 170 & 0.3 & 1500 & 0.42 & 350.56 & 3.76 \\
\hline 8 & 170 & 0.3 & 2500 & 0.42 & 222.73 & 5.50 \\
\hline 9 & 150 & 0.3 & 2000 & 0.22 & 178.73 & 5.18 \\
\hline 10 & 190 & 0.3 & 2000 & 0.22 & 270.88 & 6.13 \\
\hline 11 & 150 & 0.3 & 2000 & 0.42 & 151.89 & 3.58 \\
\hline 12 & 190 & 0.3 & 2000 & 0.42 & 334.17 & 4.30 \\
\hline 13 & 170 & 0.2 & 1500 & 0.32 & 349.37 & 3.92 \\
\hline 14 & 170 & 0.4 & 1500 & 0.32 & 289.55 & 6.50 \\
\hline 15 & 170 & 0.2 & 2500 & 0.32 & 228.30 & 4.98 \\
\hline 16 & 170 & 0.4 & 2500 & 0.32 & 178.18 & 7.22 \\
\hline 17 & 150 & 0.3 & 1500 & 0.32 & 231.46 & 3.09 \\
\hline 18 & 190 & 0.3 & 1500 & 0.32 & 387.86 & 4.56 \\
\hline 19 & 150 & 0.3 & 2500 & 0.32 & 148.76 & 3.80 \\
\hline 20 & 190 & 0.3 & 2500 & 0.32 & 261.91 & 5.50 \\
\hline 21 & 170 & 0.2 & 2000 & 0.22 & 267.17 & 5.44 \\
\hline 22 & 170 & 0.4 & 2000 & 0.22 & 213.55 & 8.40 \\
\hline 23 & 170 & 0.2 & 2000 & 0.42 & 332.03 & 3.67 \\
\hline 24 & 170 & 0.4 & 2000 & 0.42 & 251.86 & 6.22 \\
\hline 25 & 170 & 0.3 & 2000 & 0.32 & 242.02 & 4.61 \\
\hline 26 & 170 & 0.3 & 2000 & 0.32 & 236.96 & 4.41 \\
\hline 27 & 170 & 0.3 & 2000 & 0.32 & 238.73 & 4.18 \\
\hline 28 & 170 & 0.3 & 2000 & 0.32 & 245.56 & 4.8 \\
\hline 29 & 170 & 0.3 & 2000 & 0.32 & 243.03 & 4.5 \\
\hline
\end{tabular}

parameter values, GRC, GRG, and rank determined using the equations enumerated under stages $1-3$ are presented in Table 7. The optimal parameter values were determined based on the GRA results, while the ranks were obtained using the GRG. In this work, the best and worst process parameter values of the machining process were used to assess the effects of those parameters on MRR and $R_{\mathrm{a}}$.

\section{Results and discussion}

AWJ milling is a deterministic process because it involves several input parameters, which should be considered in the optimisation of the process conditions such as for producing pockets in a workpiece. The response surface methodology (RSM) may be used for single response optimisation of the milling process. However, in the practical application of AWJ milling to pocket milling in Hastelloy
C-276, it is desirable for the process to be executed with the maximum MRR and minimum $R_{\mathrm{a}}$. Hence, in this work, the optimisation of the AWJ milling parameters was conducted using the multi-response optimisation technique. Workpieces milled under various operation conditions were analysed to determine the most suitable process parameters. This necessitated the employment of the grey relational analysis method.

\subsection{Response surface graph analysis for MRR}

The machining data analysis and results are described and discussed below. Analysis of variance (ANOVA) was performed on the MRR data, and the significances of the individual parameters were determined at a $95 \%$ confidence level. Regression equation is generated based on factorial interactions and achieved $\mathrm{R}^{2}$ value of 0.961 , Mean square error of 124.413 , root mean square error of $11.154 \mathrm{~mm}^{3} /$ 


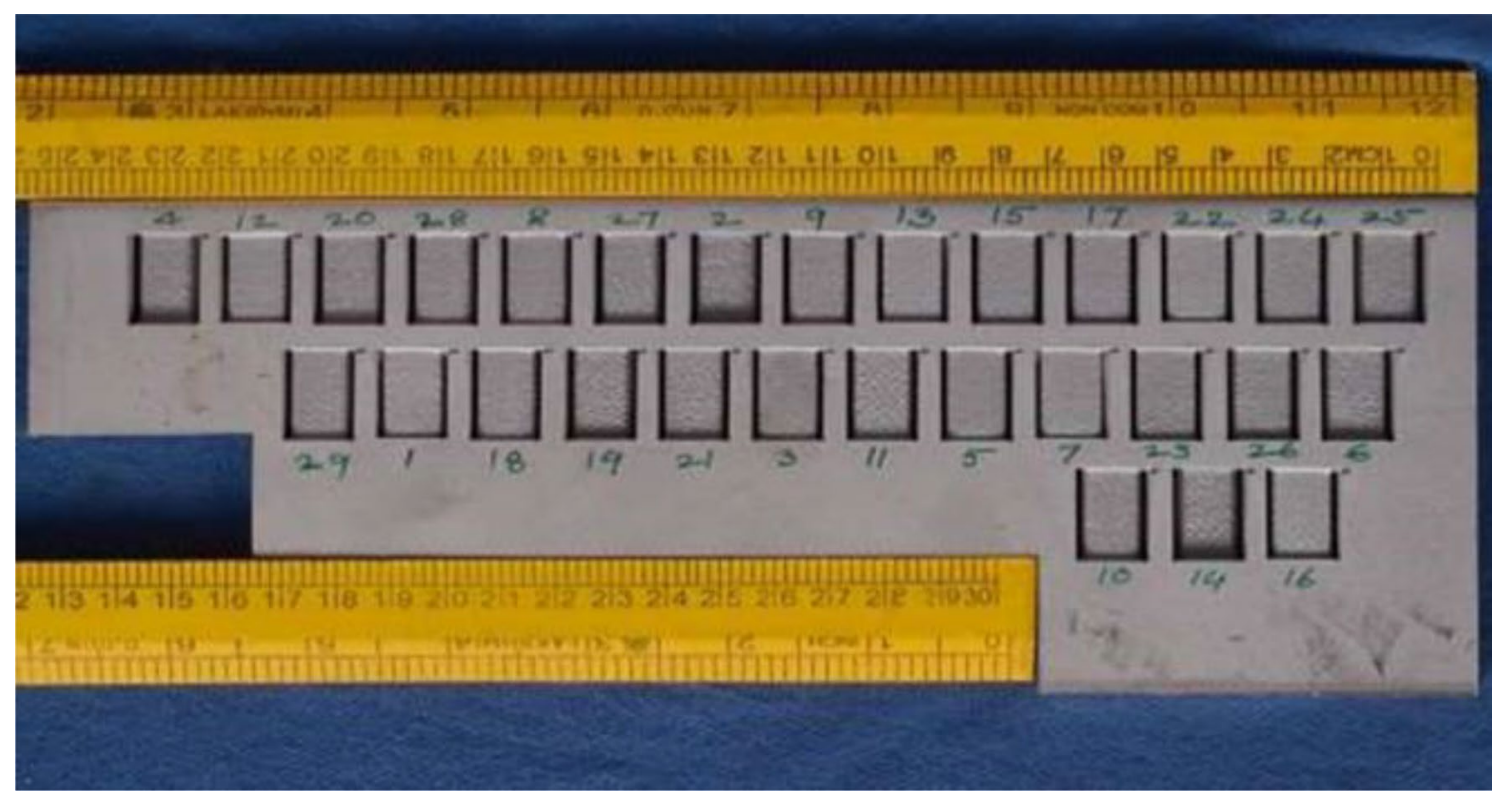

Fig. 4 Milled pockets in Hastelloy C-276 workpiece

min, mean absolute error of $9.029 \mathrm{~mm}^{3} / \mathrm{min}$, and mean percentage error of $3.6128 \%$, which indicates that parameters are well fitted with the model. As can be observed from Table 5, the waterjet pressure, traverse rate, and step over were the most significant parameters for maximising the MRR.

Figure 6 shows the response surface graphs for MRR, from which it can be observed that the parameter can be increased using various combinations of the AWJ milling process parameters for Hastelloy C-276. Figure 6a shows that a higher MRR can be achieved by varying the waterjet pressure from 150 to $190 \mathrm{MPa}$ and the step over from 0.2 to $0.4 \mathrm{~mm}$, while maintaining the traverse rate and abrasive flow rate at constant values. As can be observed from Fig. 6a, the MRR increases with increase in the waterjet pressure from 150 to $190 \mathrm{MPa}$, and the step over from high

Table 5 ANOVA for MRR

\begin{tabular}{llrrrr}
\hline Source & Sum of square & $d f$ & Mean square & $F$ value & $\begin{array}{l}P \text { value } \\
\text { Prob }>F\end{array}$ \\
\hline Model & $1.122 \mathrm{E}+005$ & 10 & 11224.16 & 45.10 & $<0.0001$ \\
P & 56442.16 & 1 & 56442.16 & 226.82 & $<0.0001$ \\
SO & 11596.88 & 1 & 11596.88 & 46.60 & $<0.0001$ \\
TR & 36351.83 & 1 & 36351.83 & 146.08 & $<0.0001$ \\
AFR & 4799.52 & 1 & 4799.52 & 19.29 & 0.0004 \\
P $\times$ SO & 24.25 & 1 & 24.25 & 0.097 & 0.7585 \\
P $\times$ TR & 467.75 & 1 & 467.75 & 1.88 & 0.1872 \\
P $\times$ AFR & 2030.72 & 1 & 2030.72 & 8.16 & 0.0105 \\
SO $\times$ TR & 23.54 & 1 & 23.54 & 0.095 & 0.7620 \\
SO $\times$ AFR & 176.28 & 1 & 176.28 & 0.71 & 0.4110 \\
TR $\times$ AFR & 328.68 & 1 & 328.68 & 1.32 & 0.2655 \\
Residual & 4479.22 & 18 & 248.85 & - & \\
Lack of Fit & 4432.06 & 14 & 316.58 & 26.85 & 0.0030 \\
Pure Error & 47.16 & 4 & 11.79 & - & -
\end{tabular}




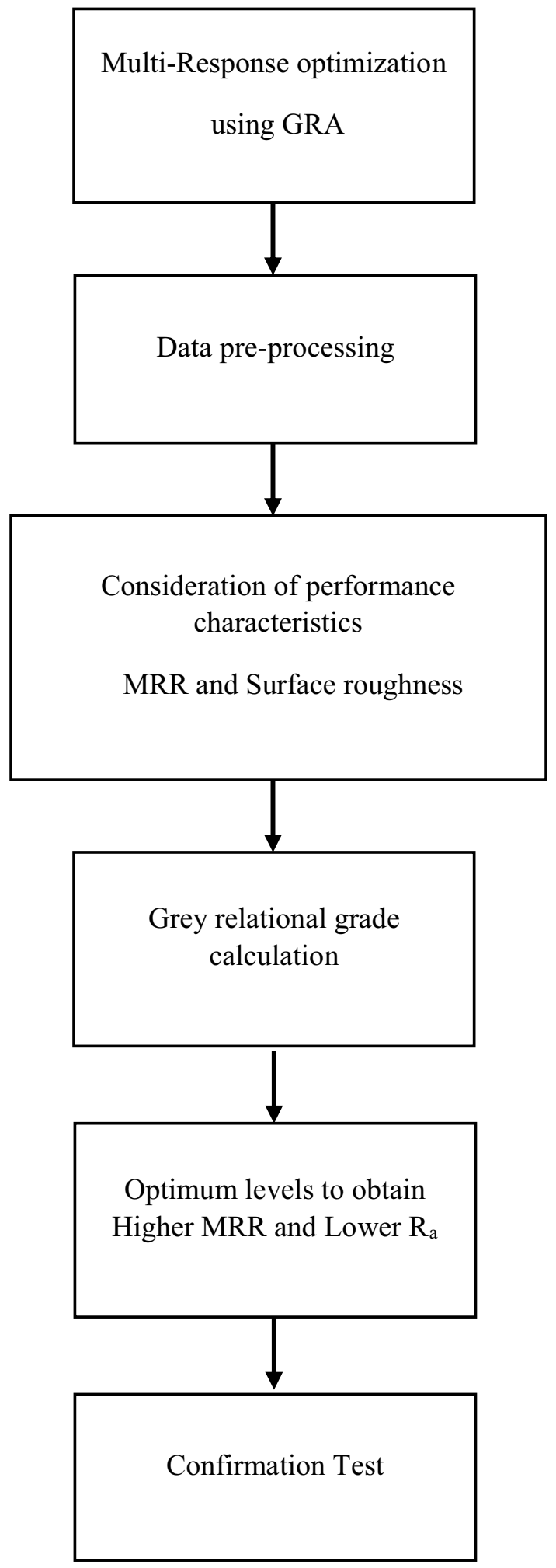

Fig. 5 Grey relational analysis flowchart level $(0.4 \mathrm{~mm})$ to low level $(0.2 \mathrm{~mm})$, for an abrasive flow rate of $0.42 \mathrm{~kg} / \mathrm{min}$, and traverse rate of $1500 \mathrm{~mm} / \mathrm{min}$. The maximum MRR achievable under these conditions is $435.03 \mathrm{~mm}^{3} / \mathrm{min}$, as shown in Fig. 6a. As described below, there is the possibility of achieving higher MRR using other combinations of process parameters.

Figure $6 \mathrm{~b}$ shows a two-dimensional (2D) surface plot of the traverse rate versus the waterjet pressure. A high MRR of $429.02 \mathrm{~mm}^{3} / \mathrm{min}$ is achieved for a traverse rate of $1500 \mathrm{~mm} / \mathrm{min}$, waterjet pressure of $190 \mathrm{MPa}$, abrasive flow rate of $0.42 \mathrm{~kg} / \mathrm{min}$, and step over of $0.2 \mathrm{~mm}$. Figure $6 \mathrm{c}$ shows a $2 \mathrm{D}$ surface plot of the abrasive flow rate versus the waterjet pressure. An MRR of $443.2 \mathrm{~mm}^{3} / \mathrm{min}$ is achieved under an abrasive flow rate of $0.42 \mathrm{~kg} / \mathrm{min}$, waterjet pressure of $190 \mathrm{MPa}$, step over of $0.2 \mathrm{~mm}$, and traverse rate of $1500 \mathrm{~mm} / \mathrm{min}$. Figure $6 \mathrm{~d}$ shows a 2D surface plot of the step over versus the traverse rate. An MRR of $444.02 \mathrm{~mm}^{3} /$ min is achieved for an abrasive flow rate of $0.42 \mathrm{~kg} / \mathrm{min}$, waterjet pressure of $190 \mathrm{MPa}$, step over of $0.2 \mathrm{~mm}$, and traverse rate of $1500 \mathrm{~mm} / \mathrm{min}$. Figure $6 \mathrm{e}$ shows the 2D surface plot of the abrasive flow rate versus the step over. An MRR of $453.2 \mathrm{~mm}^{3} / \mathrm{min}$ is achieved for an abrasive flow rate of $0.42 \mathrm{~kg} / \mathrm{min}$, step over of $0.2 \mathrm{~mm}$, traverse rate of $1500 \mathrm{~mm} / \mathrm{min}$, and waterjet pressure of $190 \mathrm{MPa}$. Figure $6 \mathrm{f}$ shows the $2 \mathrm{D}$ surface plot of the traverse rate versus the abrasive flow rate. An MRR of $443.24 \mathrm{~mm}^{3} / \mathrm{min}$ is achieved for a traverse rate of $1500 \mathrm{~mm} / \mathrm{min}$ and abrasive flow rate of $0.42 \mathrm{~kg} / \mathrm{min}$. A traverse rate of $1500 \mathrm{~mm} / \mathrm{min}$, step over of $0.2 \mathrm{~mm}$, and waterjet pressure of $190 \mathrm{MPa}$ also produce a high MRR. A high MRR is thus achieved under the aforementioned process conditions, such as a high waterjet pressure of $190 \mathrm{MPa}$, low step over of $0.2 \mathrm{~mm}$, low traverse rate of $1500 \mathrm{~mm} / \mathrm{min}$, and high abrasive flow rate of $0.42 \mathrm{~kg} / \mathrm{min}$. The following regression equation was derived from the obtained results:

$$
\begin{aligned}
& \text { MRR }=-48.01523+(2.35668 \times \mathrm{P})+(13.80117 \times \mathrm{SO}) \\
& +(0.11722 \times \mathrm{TR})-(1153.46375 \times \mathrm{AFR})-(1.23100 \times \mathrm{P} \times \mathrm{SO}) \\
& -(1.08137 \mathrm{e}-003 \times \mathrm{P} \times \mathrm{TR})+(11.26587 \times \mathrm{P} \times \mathrm{AFR}) \\
& +(0.048515 \times \mathrm{SO} \times \mathrm{TR})-(663.85000 \times \mathrm{SO} \times \mathrm{AFR}) \\
& -(0.18129 \times \mathrm{TR} \times \mathrm{AFR})
\end{aligned}
$$

The results of the present analysis indicate that a higher waterjet pressure increases the MRR, attributable to the removal of a larger amount of material from the workpiece by the increased kinetic energy of the jet. In addition, a lower step over increases the MRR through increase in the impinging waterjet per unit area of the target material. Similarly, a lower traverse rate increases the MRR by increasing the number of abrasive particles and jet exposure time. In the case of the abrasive flow rate, an 
increase in this parameter increases the MRR by increasing the number of abrasive particles that interact with the workpiece.

\subsection{Response surface graph analysis for surface roughness}

The analysis of variance (ANOVA) for surface roughness is shown Table 6. The significances of the individual parameters were determined at a $95 \%$ confidence level. Regression equation is generated based on factorial interaction and achieved $R^{2}$ value of 0.959 , mean square error of 0.0668369 , root mean square error of $0.25852 \mu \mathrm{m}$, mean absolute error of $0.22358 \mu \mathrm{m}$, and mean percentage error of $4.8770 \%$. The value of coefficient of determination $\left(R^{2}\right)$ is more than $95 \%$ and mean percentage error is less than $10 \%$, indicating that the parameters well fitted to model. As can be noticed from Table 6, the step over, abrasive flow rate, and waterjet pressure were the most significant parameters that give better $R_{\mathrm{a}}$.

Figure 7 shows the response surface graphs for $R_{\mathrm{a}}$ from which it can be observed that the parameter can be decreased using several combinations of the AWJ milling process parameters for Hastelloy C-276. Figure 7a shows that $R_{\mathrm{a}}$ can be increased by increasing the waterjet pressure from 150 to $190 \mathrm{MPa}$ and the step over from 0.2 to $0.4 \mathrm{~mm}$, while maintaining the abrasive flow rate and traverse rate at constant values. However, the water pressure of $150 \mathrm{MPa}$, step over of $0.2 \mathrm{~mm}$, an abrasive flow of $0.42 \mathrm{~kg} / \mathrm{min}$ and traverse rate of $1500 \mathrm{~mm} / \mathrm{min}$ can be used to minimise $R_{\mathrm{a}}$. The minimum $R_{\mathrm{a}}$ achievable under the considered parameter combinations was approximately $2.98 \mu \mathrm{m}$, as can be observed from Fig. $7 \mathrm{a}$.

Figure $7 \mathrm{~b}$ shows the $2 \mathrm{D}$ surface plot of the waterjet pressure versus the traverse rate. An $R_{\mathrm{a}}$ of $2.85 \mu \mathrm{m}$ is obtained for a traverse rate of $1500 \mathrm{~mm} / \mathrm{min}$ and waterjet pressure of $150 \mathrm{MPa}$. Figure $7 \mathrm{c}$ shows the 2D surface plot of the abrasive flow rate versus the waterjet pressure, from which it can be seen that an $R_{\mathrm{a}}$ of $2.86 \mu \mathrm{m}$ is obtained for an abrasive flow rate of $0.42 \mathrm{~kg} / \mathrm{min}$, waterjet pressure of $150 \mathrm{MPa}$, step over of $0.2 \mathrm{~mm}$, and traverse rate of $1500 \mathrm{~mm} / \mathrm{min}$. Figure $7 \mathrm{~d}$ shows the 2D surface plot step over versus traverse rate, from which can be seen that an $R_{\mathrm{a}}$ value of $3.02 \mu \mathrm{m}$ is obtained for an abrasive flow rate of $0.42 \mathrm{~kg} / \mathrm{min}$ and waterjet pressure of $150 \mathrm{MPa}$. Figure $7 \mathrm{e}$ shows the $2 \mathrm{D}$ surface plot of the abrasive flow rate versus step over. An $R_{\mathrm{a}}$ of $3.16 \mu \mathrm{m}$ is obtained for an abrasive flow rate of $0.42 \mathrm{~kg} / \mathrm{min}$, step over of $0.2 \mathrm{~mm}$, traverse rate of $1500 \mathrm{~mm} / \mathrm{min}$, and waterjet pressure of $150 \mathrm{MPa}$. Figure $7 \mathrm{f}$ shows the $2 \mathrm{D}$ surface plot of the abrasive flow rate versus traverse rate, from which it can be seen that an $R_{\mathrm{a}}$ value of $2.76 \mu \mathrm{m}$ is obtained for a traverse rate of $1500 \mathrm{~mm} / \mathrm{min}$ and abrasive flow rate of $0.42 \mathrm{~kg} / \mathrm{min}$ (Fig. 7). The $R_{\mathrm{a}}$ can be minimised by maintaining the traverse rate at a low value of $1500 \mathrm{~mm} / \mathrm{min}$, the step over at a low value of $0.2 \mathrm{~mm}$, and the waterjet pressure at a low value of $150 \mathrm{MPa}$. The following regression equation was derived from the obtained results:
Table 6 ANOVA of the surface roughness $\left(R_{\mathrm{a}}\right)$

\begin{tabular}{llllll}
\hline Source & Sum of square & Df & Mean square & $F$ value & $\begin{array}{l}P \text { value } \\
\text { Prob }>F\end{array}$ \\
\hline Model & 45.44 & 14 & 3.25 & 23.56 & $<0.0001$ \\
P & 3.29 & 1 & 3.29 & 23.88 & $<0.0002$ \\
SO & 23.22 & 1 & 23.22 & 168.49 & $<0.0001$ \\
TR & 2.80 & 1 & 2.8 & 20.29 & 0.0005 \\
AFR & 7.01 & 1 & 7.01 & 50.9 & $<0.0001$ \\
P $\times$ SO & $7.744 E-003$ & 1 & $7.744 E-03$ & 0.056 & 0.816 \\
P $\times$ TR & 0.015 & 1 & 0.015 & 0.11 & 0.7503 \\
P $\times$ AFR & 0.015 & 1 & 0.015 & 0.11 & 0.7493 \\
SO $\times$ TR & 0.031 & 1 & 0.031 & 0.22 & 0.6427 \\
SO $\times$ AFR & 0.041 & 1 & 0.041 & 0.3 & 0.5922 \\
TR $\times$ AFR & 0.32 & 1 & 0.32 & 2.29 & 0.1526 \\
Residual & 1.93 & 18 & 0.14 & - & - \\
Lack of Fit & 1.70 & 14 & 0.17 & 2.91 & 0.1577 \\
Pure Error & 0.23 & 4 & 0.058 & - & - \\
Cor Total & 47.37 & 28 & - & - & -
\end{tabular}




$$
\begin{aligned}
R_{\mathrm{a}} & =-13.58386+(0.35574 \times \mathrm{P})-(35.71883 \times \mathrm{SO}) \\
& -(3.46945 \mathrm{e}-003 \times \mathrm{TR})-(46.03093 \times \mathrm{AFR}) \\
& +(0.022000 \times \mathrm{P} \times \mathrm{SO})+(6.02500 \mathrm{e}-006 \times \mathrm{P} \times \mathrm{TR}) \\
& -(0.030250 \times \mathrm{P} \times \mathrm{AFR})-(1.76000 \mathrm{e}-003 \times \mathrm{SO} \times \mathrm{TR}) \\
& -(10.17500 \times \mathrm{SO} \times \mathrm{AFR})+(5.61500 \mathrm{e}-003 \times \mathrm{TR} \times \mathrm{AFR})
\end{aligned}
$$

Analysis of the results revealed that a lower waterjet pressure gives better $R_{\mathrm{a}}$, attributable to the sufficient kinetic energy of the abrasive particles, their uniform mixing in the chamber, and their interaction with the workpiece. A low step over decreases $R_{\mathrm{a}}$ because it increases the amount of the impinging waterjet per unit area of the target material and hence the uniformity of the material removal. A low traverse rate also decreases $R_{\mathrm{a}}$, by increasing the number of abrasive particles that interact with the workpiece and increasing the jet exposure time. In the case of the abrasive flow rate, a higher value gives better $R_{\mathrm{a}}$ by increasing the number of abrasive particles and the uniformity of their distribution over the workpiece.

Thus, in this work, the selected experimental combinations were chosen on the basis of the grey relational grade values (Table 7), and the optimal combination of the process parameters for the AWJ milling of Hastelloy C-276 was determined. The selected combinations are Exp-2, Exp-16, Exp18, and Exp-22. The selected AWJ milling conditions were studied using surface morphology and surface topography.

\subsection{Effect of selected combination parameters on MRR and $R_{\mathrm{a}}$}

\subsubsection{MRR}

As noted earlier, the AWJ milling experiments were performed using Hastelloy C-276 workpieces and the process parameters were selected by the GRA. The value of MRR was observed to be different for all the considered experimental conditions. The experimental results showed that the MRR under the conditions of Exp-18 was higher followed by Exp-2 than that of other experimental conditions. Typically, an increase in the water flow pressure increases the kinetic energy of the waterjet, resulting in greater material removal. In this work, a water flow pressure of $190 \mathrm{MPa}$ produced the highest MRR. Using a step over of $0.2 \mathrm{~mm}$ and $0.3 \mathrm{~mm}$ also increased the MRR compared with $0.4 \mathrm{~mm}$ because the smaller step over increased the number of passes of the jet over the work piece. The traverse rate of the jet for Exp-2 (best) and Exp-22 (worst) was the same. Typically, high traverse rate has a smaller effect on the MRR because it shortens the exposure time of the jet on the workpiece, causing the MRR to saturate. An abrasive mass flow rate also improves the MRR because the high-pressure energy of the water flow is directly transferred as kinetic energy to the abrasive particles. The high velocity of the jet increases the amount of impinging abrasive particles and their interaction with the workpiece. In addition, the number of abrasive particles colliding with each other in the mixing chamber increases with increase in abrasive flow rate, resulting in fragmentation of the particles into a larger number of smaller particles with sharp edges, which enhance the MRR.

\subsubsection{Surface morphology}

Scanning electron microscopy (SEM) images were obtained for Exp-2, Exp-16, Exp-18, and Exp-22, as, respectively, shown in Fig. 8. The values of $R_{\mathrm{a}}$ achieved in these experiments were approximately 3.60, 7.22, 4.56, and $8.40 \mu \mathrm{m}$, respectively. It can be observed from the SEM images that, under the machining conditions of Exp-16 and Exp-22 (Fig. 8c,d), the workpiece surface was dominated by deep ploughs owing to the water jet being normal to the workpiece, with the jet pressure of $170 \mathrm{MPa}$ and abrasive mass flow rate causing randomly distributed impacts on the workpiece. The random distribution of the abrasive particles reduced the kinetic energy of the abrasive waterjet mixture in the mixing tube during the milling process, resulting in the generation of the ploughed milled surface. Also, traverse rate has an effect by increasing the number of abrasive particles that interact with the workpiece and the jet exposure time.

Conversely, under the conditions of Exp-2 and Exp-18 (Fig. 8a,b), including the abrasive mass flow rate of $0.32 \mathrm{~kg} /$ min, a larger number of abrasive particles were fractured in the mixing tube, resulting in a condition that produced micro-ploughing on the milled surface.

A larger number of abrasive particles were embedded in the milled surface under the machining conditions of Exp-16 \& Exp-22 compared with Exp-2 and Exp-18. This was because the abrasive particles in the mixing tube were normal to the workpiece and insufficient kinetic energy would allow adhesion of the abrasive particles to the workpiece, with subsequent adhesions causing the earlier particles to embed in the workpiece under the action of the waterjet. However, under the conditions of Exp-2 and Exp-18, the high kinetic energy of the abrasive particles caused them to bounce off the workpiece, with only a few adhering to the milled surface. A small pit was observed in the milled surface of Exp-2 and Exp-18 as can be seen in Fig. 8a, b, whereas a large pit was observed in that of Exp-16 and Exp-22, as seen in Fig. 8c,d. The pit was due to the eventual removal of the initial embedded particles, resulting in the erosion of more material from that part of the workpiece. 

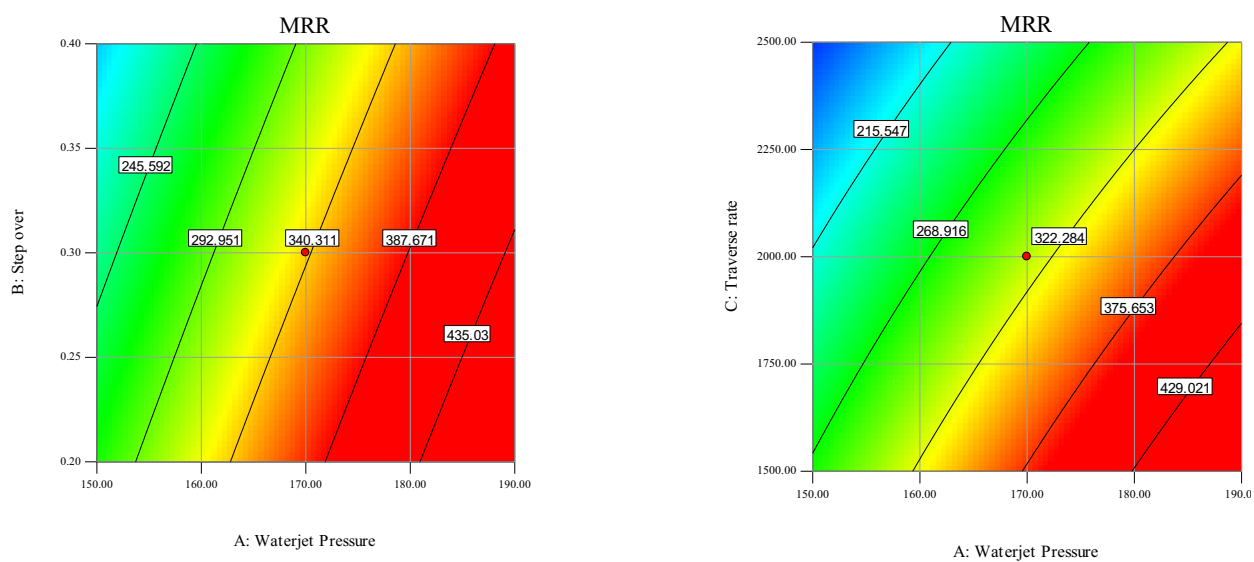

(a) Step over vs. Waterjet pressure (low traverse rate and high abrasive flow rate)

(b) Traverse rate vs. Waterjet pressure (low step over and high abrasive flow rate)
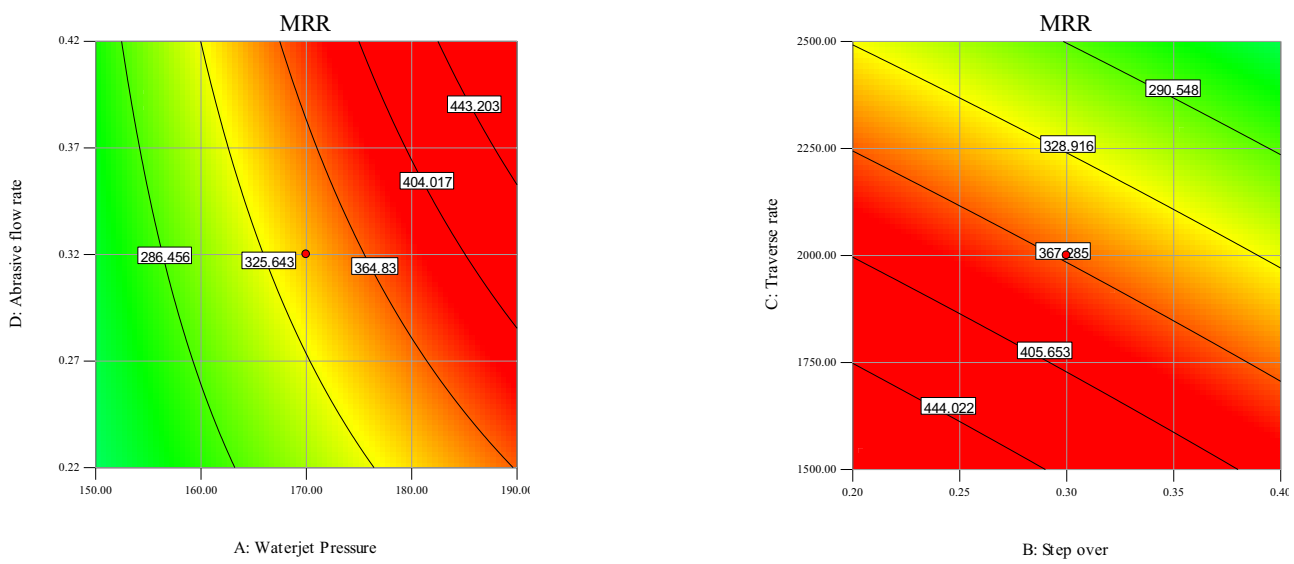

B: Step over

(c) Abrasive flow rate vs. waterjet pressure (low step over and low traverse rate)

(d) Step over vs. traverse rate (high waterjet pressure and high abrasive flow rate)
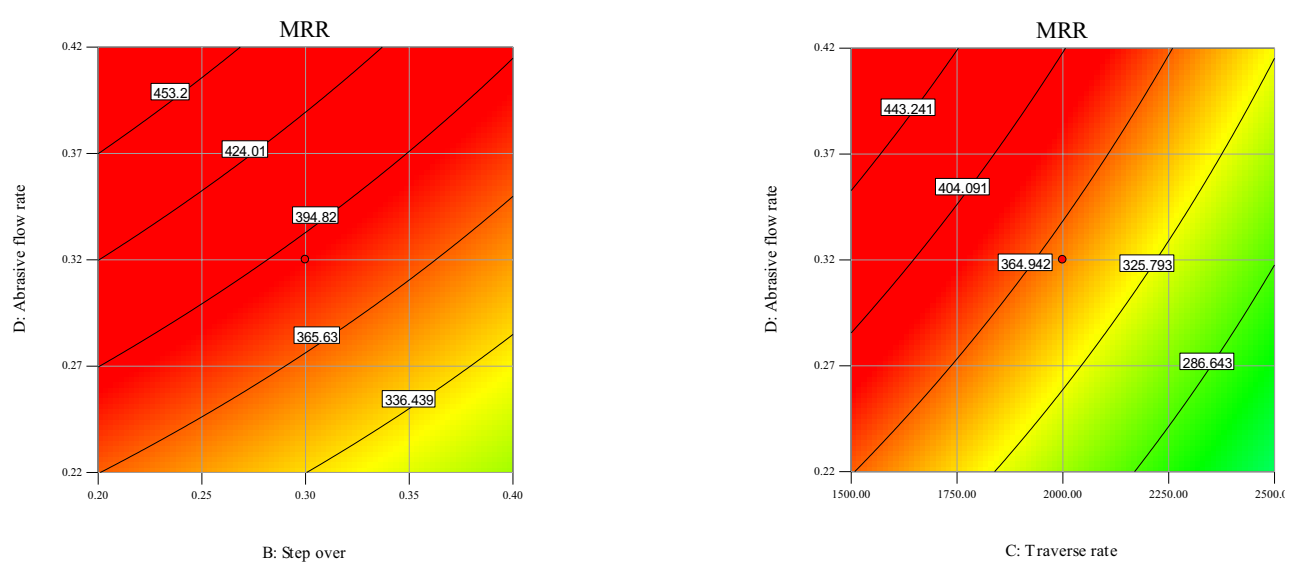

(e) Abrasive flow rate vs. step over (high waterjet pressure and low traverse rate)

(f) Traverse rate vs. abrasive flow rate (low step over and high waterjet pressure)

Fig. 6 Two-dimensional response surface graphs of MRR 


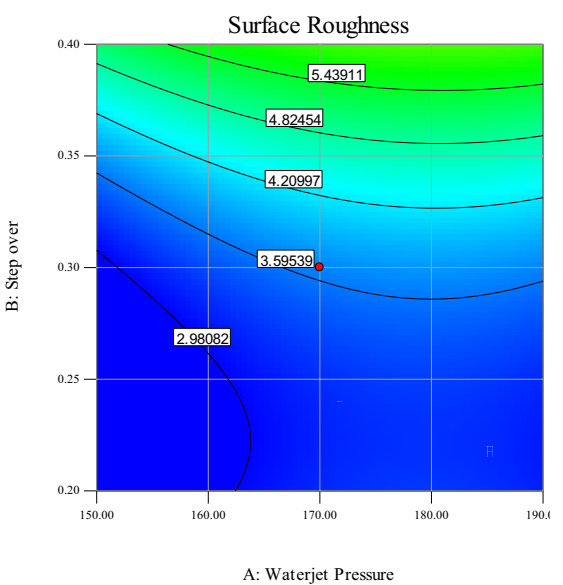

(a) Waterjet pressure vs. step over (low traverse rate and high abrasive flow rate)

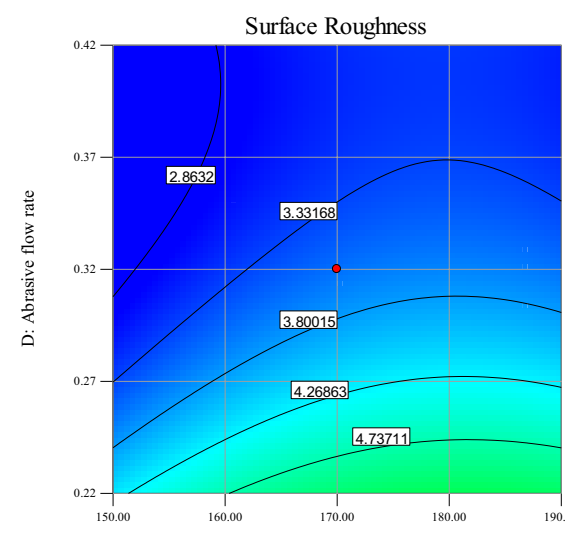

A: Waterjet Pressure

(c) Abrasive flow rate vs. waterjet pressure (low step over and low traverse rate)

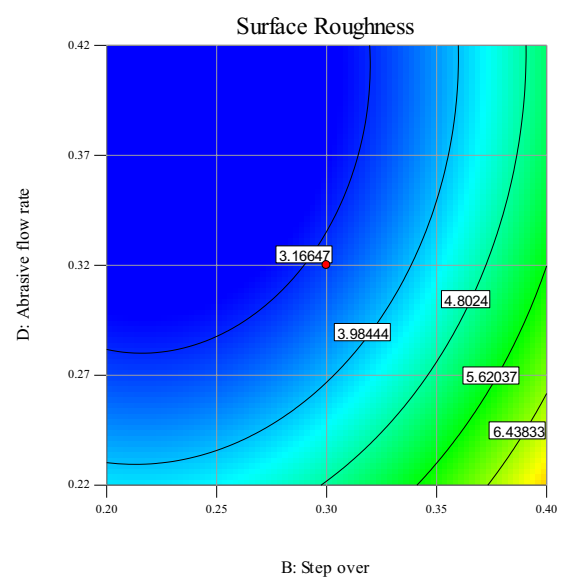

(e) Abrasive flow rate vs. step over (low waterjet pressure and low traverse rate)

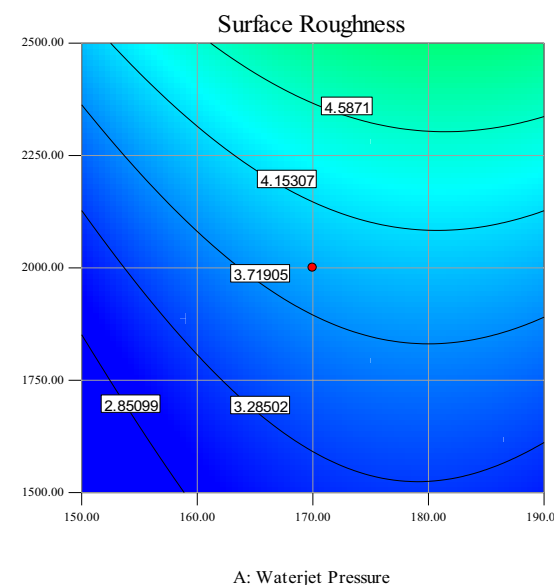

(b) Waterjet pressure vs. traverse rate (low step over and high abrasive flow rate)

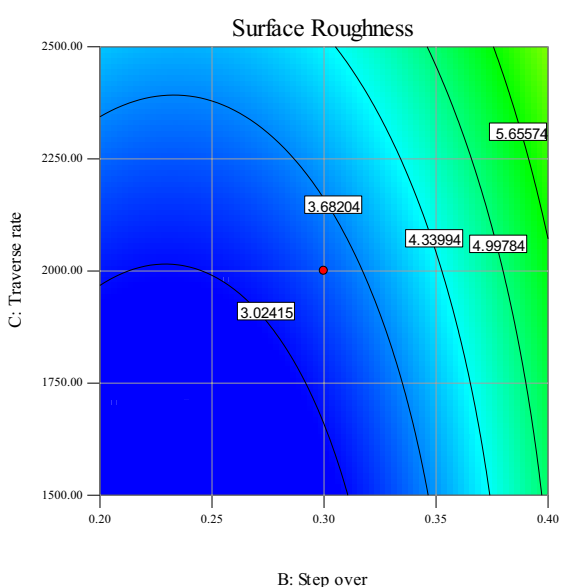

(d) Step over vs. traverse rate (high abrasive flow rate and low waterjet pressure)

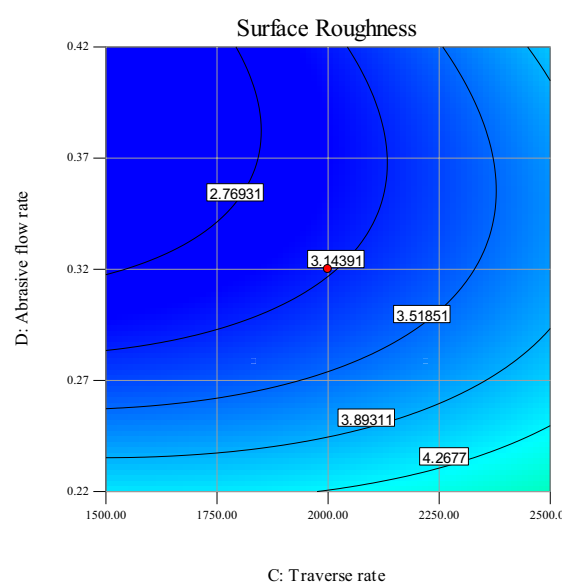

(f) Abrasive flow rate vs. traverse rate (low waterjet pressure and low step over)

Fig. 7 Two-dimensional response surface graphs of $R_{\mathrm{a}}$ 
Table 7 Normalised GRC and GRG values

\begin{tabular}{|c|c|c|c|c|c|c|}
\hline \multirow[t]{2}{*}{ Exp. no } & \multicolumn{2}{|l|}{ Normalised value } & \multicolumn{2}{|c|}{ Grey coefficient value } & \multirow{2}{*}{$\begin{array}{l}\text { Grey relation grade } \\
\text { GRG }\end{array}$} & \multirow[t]{2}{*}{ Rank } \\
\hline & $\operatorname{MRR}\left(\mathrm{mm}^{3} / \mathrm{min}\right)$ & $\begin{array}{l}\text { Surface } \\
\text { roughness } \\
(\mu \mathrm{m})\end{array}$ & $\operatorname{MRR}\left(\mathrm{mm}^{3} / \mathrm{min}\right)$ & $\begin{array}{l}\text { Surface } \\
\text { roughness } \\
(\mu \mathrm{m})\end{array}$ & & \\
\hline 1 & 0.288 & 1.000 & 0.413 & 1.000 & 0.706 & 6 \\
\hline 2 & 0.892 & 0.883 & 0.823 & 0.811 & 0.817 (best) & 1 \\
\hline 3 & 0.038 & 0.431 & 0.342 & 0.468 & 0.405 & 27 \\
\hline 4 & 0.601 & 0.282 & 0.556 & 0.410 & 0.483 & 21 \\
\hline 5 & 0.558 & 0.585 & 0.531 & 0.547 & 0.539 & 14 \\
\hline 6 & 0.175 & 0.471 & 0.377 & 0.486 & 0.432 & 26 \\
\hline 7 & 0.844 & 0.854 & 0.762 & 0.774 & 0.768 & 3 \\
\hline 8 & 0.309 & 0.533 & 0.420 & 0.517 & 0.469 & 23 \\
\hline 9 & 0.125 & 0.593 & 0.364 & 0.551 & 0.457 & 25 \\
\hline 10 & 0.511 & 0.417 & 0.505 & 0.462 & 0.483 & 22 \\
\hline 11 & 0.013 & 0.886 & 0.336 & 0.814 & 0.575 & 9 \\
\hline 12 & 0.775 & 0.755 & 0.690 & 0.671 & 0.680 & 8 \\
\hline 13 & 0.839 & 0.824 & 0.756 & 0.740 & 0.748 & 4 \\
\hline 14 & 0.589 & 0.349 & 0.549 & 0.434 & 0.491 & 20 \\
\hline 15 & 0.333 & 0.628 & 0.428 & 0.574 & 0.501 & 19 \\
\hline 16 & 0.123 & 0.217 & 0.363 & 0.390 & 0.376 & 28 \\
\hline 17 & 0.346 & 0.976 & 0.433 & 0.954 & 0.694 & 7 \\
\hline 18 & 1.000 & 0.707 & 1.000 & 0.630 & 0.815 & 2 \\
\hline 19 & 0.000 & 0.847 & 0.333 & 0.765 & 0.549 & 11 \\
\hline 20 & 0.473 & 0.533 & 0.487 & 0.517 & 0.502 & 18 \\
\hline 21 & 0.466 & 0.544 & 0.484 & 0.523 & 0.503 & 17 \\
\hline 22 & 0.271 & 0.000 & 0.407 & 0.333 & 0.370 (worst) & 29 \\
\hline 23 & 0.766 & 0.870 & 0.682 & 0.794 & 0.738 & 5 \\
\hline 24 & 0.431 & 0.401 & 0.468 & 0.455 & 0.461 & 24 \\
\hline 25 & 0.390 & 0.696 & 0.450 & 0.622 & 0.536 & 15 \\
\hline 26 & 0.369 & 0.734 & 0.442 & 0.653 & 0.548 & 12 \\
\hline 27 & 0.376 & 0.777 & 0.445 & 0.691 & 0.568 & 10 \\
\hline 28 & 0.405 & 0.657 & 0.457 & 0.593 & 0.525 & 16 \\
\hline 29 & 0.394 & 0.710 & 0.452 & 0.633 & 0.543 & 13 \\
\hline
\end{tabular}

\subsubsection{Surface topography}

The 3D surface height parameters such as the skewness $\left(S_{\text {sk }}\right)$, kurtosis $\left(S_{\mathrm{ku}}\right)$, profile mean height $\left(S_{\mathrm{a}}\right)$, maximum profile peak height $\left(S_{\mathrm{p}}\right)$, maximum profile pit (or) valley depth $\left(S_{v}\right)$, and maximum profile height $\left(S_{t}\right)$ for Exp-2, Exp-18, Exp-16, and Exp-22 were compared to examine the surface topography of the milled pockets with respect to the machining conditions. Figure 9 shows the 3D surface topographies of the surfaces machined under the conditions of Exp-2, Exp-18, Exp-16, and Exp-22, respectively. The profile means height values of $S_{a}$ for these cases were determined to be $2.433,3.847,7.273$, and $9.693 \mu \mathrm{m}$, respectively. This clearly indicates that the surface generated under the conditions of Exp-22 was poorer followed by Exp-16, attributable to the aforementioned deep ploughing. Randomly distributed peaks and valleys were observed in the milled surfaces in all cases because the material removal through erosion by the high kinetic energy waterjet was implemented at an angle normal to the surface. The process involved randomly distributed abrasive particles and dynamic action of their cutting head induced by variation of the traverse rate. A large number of pits, plough, and grooves were thus created in the milled surface. Upward deflection of the abrasive waterjet also worsened the surface roughness [18]. The measurement results of the other 3-D surface topography parameters for selected experimental conditions are presented in Table 8.

As can be observed form Table 8, the $S_{p^{\prime}} S_{v}$ and $S_{t}$ values for Exp-22 were higher than the remaining conditions. This is because parametric combination of Exp-22 is more randomly distributed impact on the workpiece especially as the step over increases the jet exposer area is reduced which leads to non-uniform surface generation compared 
Fig. 8 SEM image of machining conditions
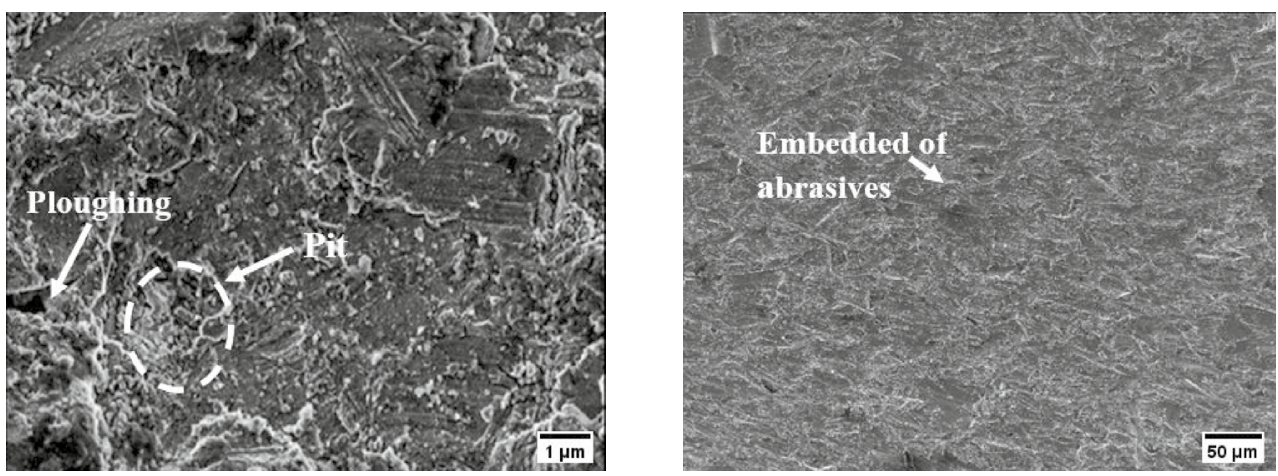

(a) Surface obtained under machining conditions of Exp-2
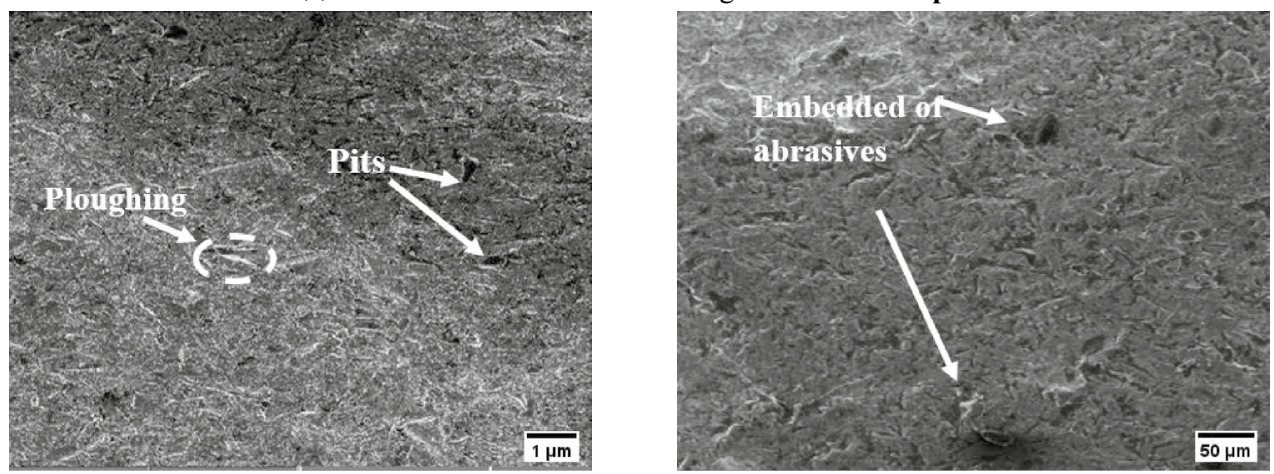

(b) Surface obtained under machining conditions of Exp-18
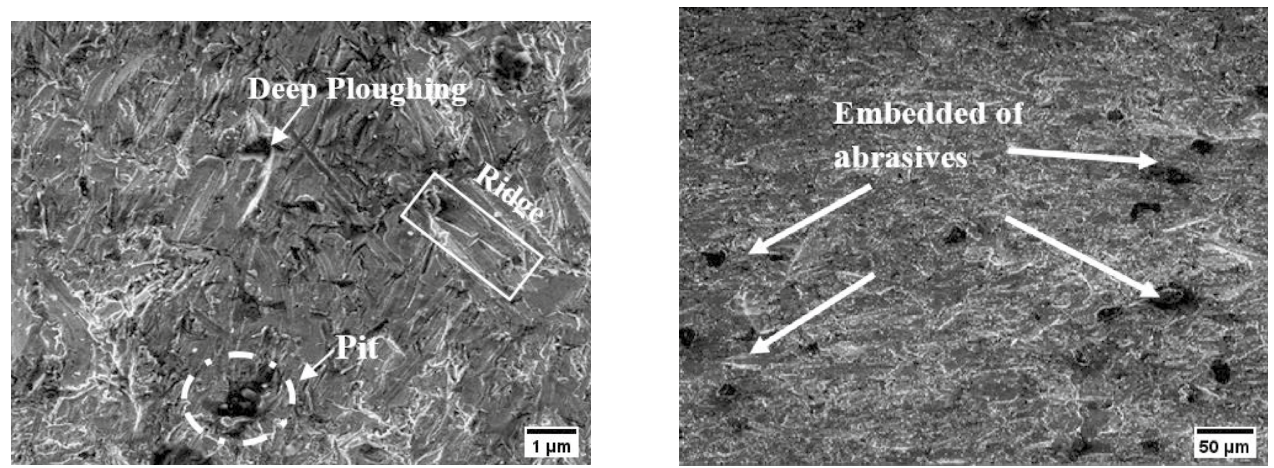

(c) Surface obtained under machining conditions of Exp-16
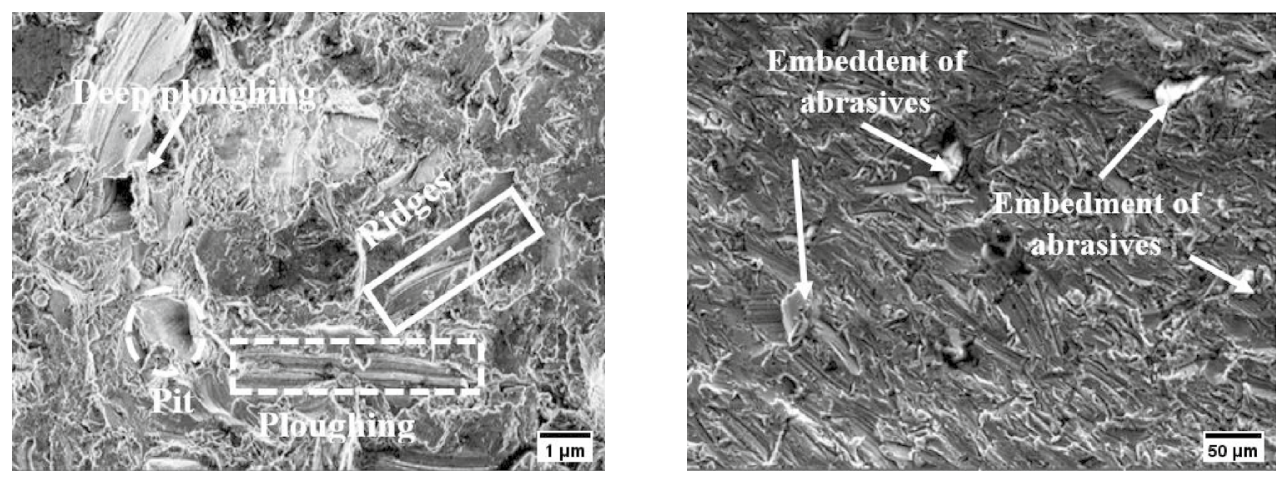

(d) Surface obtained under machining conditions of Exp-22 


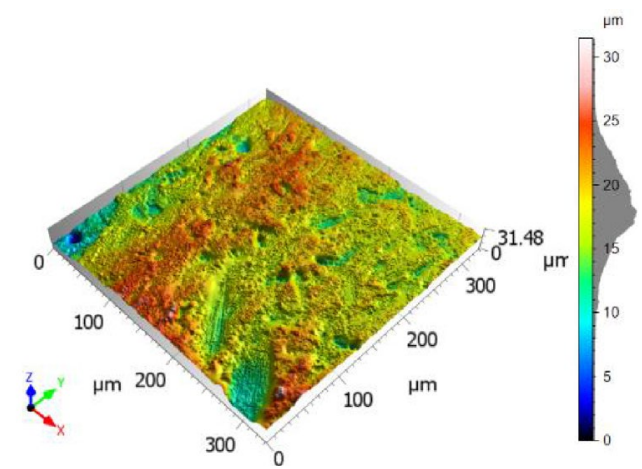

(a) Milled surface of Exp-2

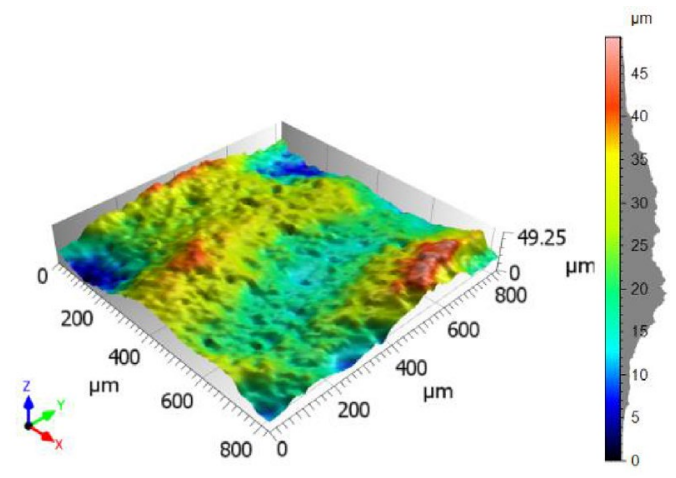

(b) Milled surface of Exp-18

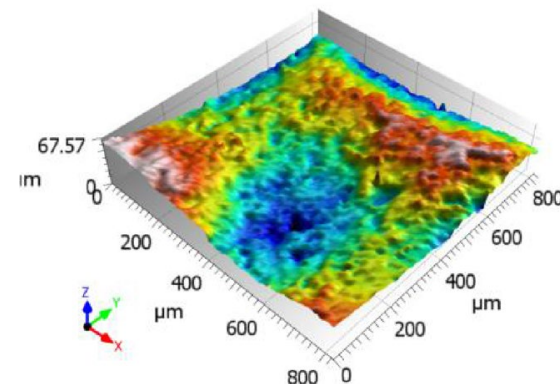

(c) Milled surface of Exp-16
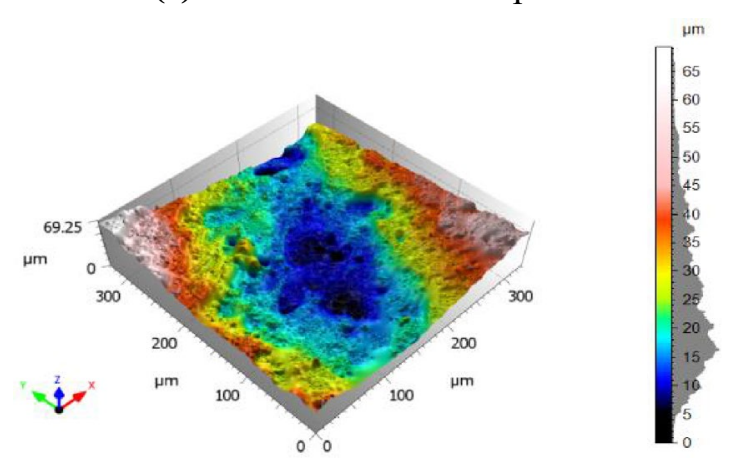

(d) Milled surface of Exp-22

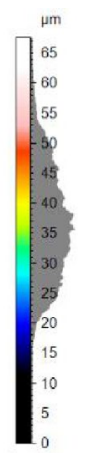

Fig. 9 Three-dimensional topology of milled surfaces

Table 8 Surface topography parameters

\begin{tabular}{lllllll}
\hline $\begin{array}{l}\text { Machining condi- } \\
\text { tion }\end{array}$ & Ssk & Sku & Sa $\mu \mathrm{m}$ & Sp $\mu \mathrm{m}$ & Sv $\mu \mathrm{m}$ & St $\mu \mathrm{m}$ \\
\hline Exp-2 & -0.026 & 2.803 & 2.433 & 13.164 & 18.334 & 31.498 \\
Exp-16 & -0.218 & 4.203 & 7.273 & 30.954 & 36.627 & 67.57 \\
Exp-18 & -0.045 & 2.958 & 3.847 & 24.455 & 24.857 & 49.312 \\
Exp-22 & -0.433 & 4.593 & 9.693 & 44.267 & 24.713 & 68.98 \\
\hline
\end{tabular}

with Exp-2 and Exp-18. Also, energy of the jet during Exp22 and Exp-16 is resulted in the production of more peaks and valleys compared to Exp-2 and Exp-18. A $S_{\text {sk }}$ value of $<0$ indicates the predominance of valleys in the surface of the milled pocket, due to the effect of the remaining energy of the abrasive particles after their initial interaction with the workpiece. Generally, $S_{\mathrm{ku}}$ is a measure of the transitions between the peaks and valleys in the machined surface. In the case of the surface obtained in Exp-2 and Exp-18 the $S_{\mathrm{ku}}$ value of 2.803 and 2.958 , which is less than 3.00 , indicates gradual transitions. Conversely, the surface obtained in Exp-16 and Exp-22 has a $S_{k u}$ value of 4.203 and 4.593, indicating sharp transitions between very high peaks and deep valleys. These $S_{\mathrm{ku}}$ values confirm that a smoother machined surface is obtained under the conditions of Exp-2 followed by Exp-18.

\section{Conclusions}

The effects of the AWJ milling process parameters on the MRR and $R_{\mathrm{a}}$ for a Hastelloy C-276 workpiece when using the RSM approach were investigated by GRA. Following is a summary of the results and the conclusions drawn from them. 
1. ANOVA results indicated that the waterjet pressure and traverse rate were the most significant determinants of the MRR. Among the conditions considered in the present work, a high waterjet pressure of $190 \mathrm{MPa}$, small step over of $0.2 \mathrm{~mm}$, low traverse rate of $1500 \mathrm{~mm} /$ $\mathrm{min}$, and high abrasive flow rate of $0.42 \mathrm{~kg} / \mathrm{min}$ produced the highest MRR. In addition, the step over was identified as a very significant factor of $R_{\mathrm{a}}$.

2. A low waterjet pressure of $150 \mathrm{MPa}$, low step over of $0.2 \mathrm{~mm}$, low traverse rate of $1500 \mathrm{~mm} / \mathrm{min}$, and high abrasive flow rate of $0.42 \mathrm{~kg} / \mathrm{min}$ produced the lowest $R_{\mathrm{a}}$ in the present study.

3. The use of GRA to selection of optimised parameters and the multi-response characteristics of the AWJ milling of Hastelloy C-276. GRA revealed that, among the conditions considered in this work, Exp-2 is found to be best and Exp-22 is found to be worst machining conditions.

4. Surface morphology analysis revealed that the Exp16 and Exp-22 conditions produced more ploughing, pit formation, and grit embedment in the machined surface compared with the Exp-2 and Exp-18.

5. Surface topography analysis considering factors such as skewness, kurtosis, profile mean height maximum profile peak height, maximum profile pit depth, and maximum profile height showed that higher peaks and deeper valleys were formed under the former conditions.

Acknowledgements The authors would like to thank Dr. M. Kanthababu, Professor and Head of Department, Department of Manufacturing Engineering, College of Engineering, Anna University, Chennai, for his guidance in the experiments of this study and for access to the AWJ milling machine in his department. The authors also thank Mr. Rajesh and Vetrivel of the same department for their assistance with the operation of the machine and Surface roughness measurements.

\section{References}

1. Dumbhare PA, Dubey S, Deshpande YV, Andhare AB, Barve PS (2018) Modelling and multi-objective optimization of surface roughness and kerf taper angle in abrasive water jet machining of steel. J Braz Soc Mech Sci Eng 40:259. https:// doi.org/10.1007/s40430-018-1186-5

2. Nair A, Kumanan S (2018) Optimization of size and characteristics using multi-objective grey analysis in abrasive water jet drilling of Inconel 617. J Braz Soc Mech Sci Eng 40:121. https ://doi.org/10.1007/s40430-018-1042-7

3. Nag A et al (2018) Hybrid aluminium matrix composite AWJ Turning using Olivine and Barton garnet. Int J Adv Manuf Technol 94(5-8):2293-2300. https://doi.org/10.1007/s0017 0-017-1036-0
4. Hashish M (1987) Milling with abrasive waterjets: a preliminary investigation. In: Proceedings of 4th US Waterjet Conference, Berkeley, CA, pp 1-10

5. Khidhir BA, Mohamed B (2011) Analyzing the effect of cutting parameters on surface roughness and tool wear when machining nickel based Hastelloy-276. In: IOP conference series: materials science and engineering, vol. 17, no. 11. https ://doi.org/10.1088/1757-899x/17/1/012043

6. Khidhir BA, Mohamed B (2010) Study of cutting speed on surface roughness and chip formation when machining nickelbased alloy. J Mech Sci Technol 24(5):1053-1059. https://doi. org/10.1007/s12206-010-0319-2

7. Ojmertz KMC (1993) Abrasive waterjet milling: an experimental investigation. In: Proceedings of the 7th American water jet conference, vol 2, pp 777-791

8. Hashish M (1988) Controlled-depth milling of iso-grid structures with AWJs. J Manuf Sci Eng 120(1):21-27. https://doi. org/10.1115/1.2830106

9. Pal VK, Tandon $\mathrm{P}$ (2012) A method to reduce milling time for Ti-6Al-4 V alloy for controlled depth milling using abrasive water jet machining. Adv Mater Res 383-390:1764-1768. https ://doi.org/10.4028/www.scientific.net/AMR.383-390.1764

10. Pal VK, Tandon $P$ (2013) Identification of the role of machinability and milling depth on machining time in controlled depth milling using abrasive water jet. Int J Adv Manuf Technol 66(5-8):877-881. https://doi.org/10.1007/s00170-01243732-z

11. Shipway PH, Fowler G, Pashby IR (2005) Characteristics of the surface of a titanium alloy following milling with abrasive waterjets. Wear 258(1-4):123-132. https://doi.org/10.1016/j. wear.2004.04.005

12. Gupta TVK, Tandon P, Ramkumar J, Vyas NS (2013) Influence of process parameters on the dimensions of the channels prepared using abrasive water jet machining. In: International mechanical engineering congress and exposition. American Society of Mechanical Engineers. https://doi.org/10.1115/ IMECE2013-64063

13. Haghbin N, Spelt JK, Papini M (2015) Abrasive waterjet micromachining of channels in metals: comparison between machining in air and submerged in water. Int J Mach Tools Manuf 88:108-117. https://doi.org/10.1016/j.ijmachtools.2014.09.012

14. Momber AW, Kovacevic R (2012) Principles of abrasive water jet machining. Springer, Berlin

15. Kong MC, Axinte D, Voice W (2011) Challenges in using waterjet machining of NiTi shape memory alloys: an analysis of controlled-depth milling. J Mater Process Technol 211(6):959-971. https://doi.org/10.1016/j.jmatprotec.2010.12.015

16. Haghbin N, Spelt JK, Papini M (2015) Abrasive waterjet micromachining of channels in metals: model to predict high aspect-ratio channel profiles for submerged and unsubmerged machining. J Mater Process Technol 222:399-409. https://doi. org/10.1016/j.jmatprotec.2015.03.026

17. Paul S, Hoogstrate AM, Van Luttervelt CA, Kals HJ (1988) An experimental investigation of rectangular pocket milling with abrasive water jet. J Mater Process Technol 73(1-3):179-188. https://doi.org/10.1016/S0924-0136(97)00227-6

18. Fowler G, Shipway PH, Pashby IR (2005) A technical note on grit embedment following abrasive water- jet milling of a titanium alloy. J Mater Process Technol 159(3):356-368. https://doi. org/10.1016/j.jmatprotec.2004.05.024

19. Fowler G, Shipway PH, Pashby IR (2005) Abrasive water-jet controlled depth milling of Ti6Al4V alloy-an investigation of the role of jet-workpiece traverse speed and abrasive grit size 
on the characteristics of the milled material. J Mater Process Technol 161(3):407-414. https://doi.org/10.1016/j.jmatprotec 2004.07.069

20. Babu MK, Chetty OK (2003) A study on recycling of abrasives in abrasive water jet machining. Wear 254(7-8):763-773. https:// doi.org/10.1016/S0043-1648(03)00256-4

21. Babu MK, Chetty OK (2002) Studies on recharging of abrasives in abrasive water jet machining. Int J Adv Manuf Technol 19(9):697-703. https://doi.org/10.1007/s001700200115

22. Fowler G, Pashby IR, Shipway PH (2009) The effect of particle hardness and shape when abrasive water jet milling titanium alloy Ti6Al4V. Wear 266(7-8):613-620. https://doi.org/10.1016/j. wear.2008.06.013

23. Chen FL, Siores E, Patel K, Momber AW (2002) "Minimizing particle contamination at abrasive waterjet machined surfaces by a nozzle oscillation technique. Int J Mach Tools
Manuf 42(13):1385-1390. https://doi.org/10.1016/S0890 $-6955(02) 00081-0$

24. Goutham U, Hasu BS, Chakraverti G, Kanthababu M (2016) Experimental investigation of pocket milling on Inconel 825 using abrasive water jet machining. Int J Curr Eng Technol 6(1):295-302

25. Rivero A, Alberdi A, Artaza T, Mendia L, Lamikiz A (2018) Surface properties and fatigue failure analysis of alloy 718 surfaces milled by abrasive and plain waterjet. Int J Adv Manuf Technol 94(5-8):2929-2938. https://doi.org/10.1007/s00170-017-0979-5

26. Mohankumar V, Kanthababu M (2016) Experimental investigations on depth of cut in abrasive water jet machining, of $\mathrm{Al} / \mathrm{B} 4 \mathrm{C}$ metal matrix composites. Int J Eng Res 5:322-326

Publisher's Note Springer Nature remains neutral with regard to jurisdictional claims in published maps and institutional affiliations. 